\title{
Impact of shock-wave loading regimes on structural and elastic characteristics of a single- component abrasive tool
}

\author{
Mariya Polyanchikova ${ }^{1, *}$ \\ ${ }^{1}$ Volgograd State Technical University, Machine-building technology Department, 400005 Lenin \\ Avenue, 28, Volgograd, Russia
}

\begin{abstract}
The article considers the issues of determining the elastic characteristics of a single-component abrasive tool depending on the porosity of the abrasive tool after pressing the abrasive compound studied; the method of determining the modulus of elongation and porosity based on theoretical and experimental data has been used; the dependency graph between the modulus of elongation and porosity, as well as experimental formulas reflecting these dependencies are presented. Based on the experimental and calculated data on the density, porosity and the size of the modulus of elongation, depending on the pressure of the shock wave during pressing and the initial aluminium oxide grains sizes, empirical dependences of elastic characteristics have been determined in order to predict the production of a single-component abrasive tool without a bond with predetermined properties.
\end{abstract}

\section{Introduction}

In the manufacture of standard abrasive tools on bakelite, ceramic, volcanic and other types of bonds, one of the main tasks in preparation of the molding compound, containing bond components, abrasive materials and blowing agents, is a uniform distribution of all components throughout the volume of the mold. This is achieved by thoroughly mixing the entire molding compound, so after pressing and sintering the abrasive tool gets a uniform distribution of cutting grains and pores throughout the volume. A tool with such a structure has a high cutting capacity and wear resistance. Furthermore, a tool of that kind used in the manufacture of critical parts of products operating under high loads and elevated temperatures makes it possible to withstand the specified quality parameters of the surface layer, in particular surface roughness, depth and degree of work hardening and residual stresses. [1]

\footnotetext{
*Corresponding author: MUPolyan4ikova@yandex.ru
} 


\section{The technology of manufacturing a single-component abrasive tool}

In the manufacture of single-component abrasive tools (SCAT) [2], the task of ensuring the uniform distribution of abrasive grains and pores is also one of the main tasks in the formation of their structure at the stage of preparing an abrasive compound. [3]

But when making molding sand for manufacturing a standard abrasive tool, it is enough to mix all the components thoroughly, the SCAT manufacture has a number of features.

Pressing of an abrasive powders compounds was carried out according to the scheme shown in Fig. 1.

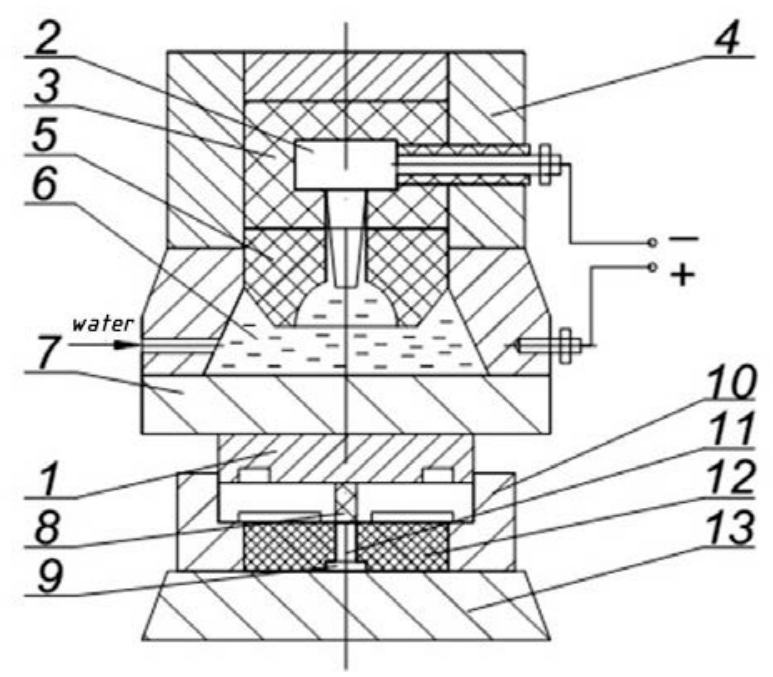

Fig. 1. Scheme of explosive pressing of a single-component abrasive tool, where 1 is the punch; 2 is the cathode; 3 and 5 are the insulators; 4 is the case of an explosive (discharge) chamber; 6 is water; 7 is the slab; 8 is the drummer; 9 is the support bar; 10 is mold housing; 11 is compressible abrasive powder; 12 is the matrix; and 13 is the press table

This paper presents the results of experimental research studies of the elastic characteristics of the SCAT tool, including the modulus of elongation, depending on the porosity of the abrasive tool after pressing the abrasive compound under study. [4]

\section{Determination of the elastic characteristics of a single-component abrasive tool}

The initial data for determining the modulus of elongation were the relationships between the density of the abrasive compound studied and pressure of the shock wave used in pressing.

According to the results of the studies, the dependencies graphs of the compacts' densities obtained at different pressures of the shock wave for different initial sizes of aluminum oxide grains were plotted and shown in Fig. 2. 


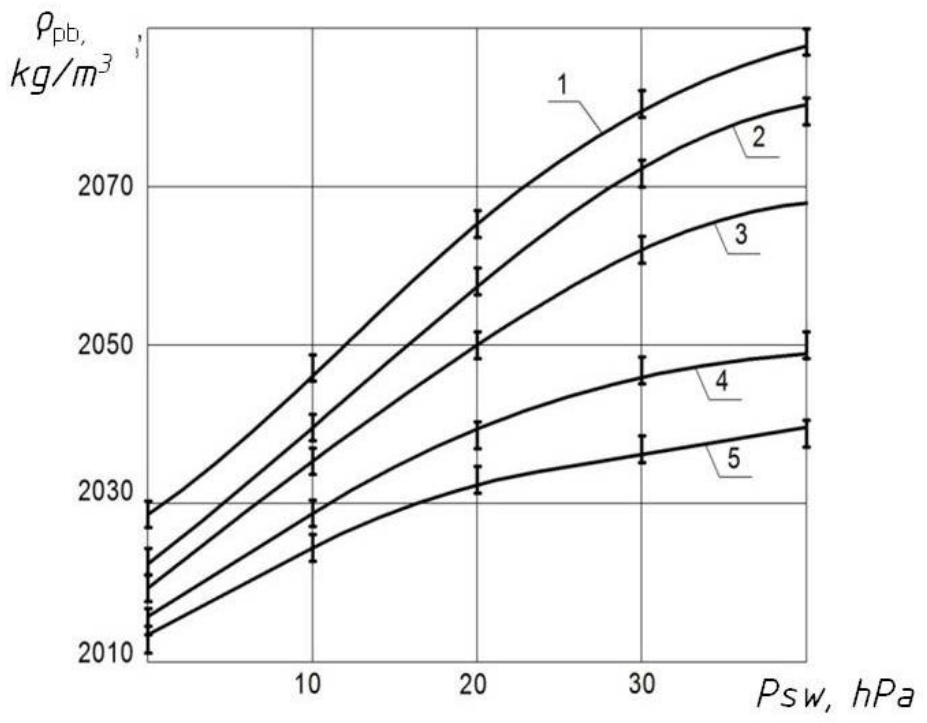

Fig. 2. The dependency graph between the pressed density of the abrasive compound and blast pressure in the shock wave front (Psw), where 1 is the Al2O3 grain size of $100 \mu \mathrm{m}$ (F 120); 2 is the $\mathrm{Al} 2 \mathrm{O} 3$ grain size of $200 \mu \mathrm{m}$ (F 80); 3 is the $\mathrm{Al} 2 \mathrm{O} 3$ grain size of $320 \mu \mathrm{m}$ (F 54); 4 is the Al2O3 grain size of $400 \mu \mathrm{m}$ (F 46); and 5 is the $\mathrm{Al} 2 \mathrm{O} 3$ grain size of $500 \mu \mathrm{m}$ (F 36).

After processing the data presented in Fig. 2 using the technique described in literature, empirical dependencies (1)-(5) were obtained that related the pressed density to the pressure of a shock wave in pressing for different grain sizes of the $\mathrm{Al}_{2} \mathrm{O}_{3}$ powder

$$
\begin{aligned}
& \rho_{100}=1982 \cdot \mathrm{P}_{s w}^{0.014} \\
& \rho_{200}=1982 \cdot \mathrm{P}_{s w}^{0.013} \\
& \rho_{300}=1993 \cdot \mathrm{P}_{s w}^{0.01} \\
& \rho_{400}=1993 \cdot \mathrm{P}_{s w}^{0.08} \\
& \rho_{500}=1989 \cdot \mathrm{P}_{s w}^{0.007}
\end{aligned}
$$

Table 1 shows the experimental and calculated data on the density, porosity and $E_{P}$ depending on the pressure of the shock wave when pressing the abrasive compound studied for the initial grain size of aluminum oxide of $100 \mu \mathrm{m}, 200 \mu \mathrm{m}, 320 \mu \mathrm{m}, 400 \mu \mathrm{m}$ and 500 $\mu \mathrm{m}$.

The porosity was determined by the formula (6) and the modulus of elongation by the formula (7):

$$
\begin{gathered}
P=\frac{3762-\rho_{p b}}{3762} \\
E_{P}=\frac{419(1+P)}{1-P}
\end{gathered}
$$

where $\rho_{\mathrm{pb}}$ is the density of a porous body.

Based on the data in Table 1, the dependency graphs were plotted between the modulus of elongation and porosity and presented in Figures 3-5. 
Table 1. Experimental and calculated data on the density, porosity and Ep value depending on the pressure of the shock wave in pressing and initial grain size of aluminum oxide

\begin{tabular}{|c|c|c|c|c|}
\hline Psw, GPa & 10 & 20 & 30 & 40 \\
\hline \multicolumn{5}{|c|}{ Initial size $\mathrm{Al}_{2} \mathrm{O}_{3}$ of $100 \mu \mathrm{m}$} \\
\hline Density, $\mathrm{kg} / \mathrm{m}^{3}$ & 2048 & 2065 & 2079 & 2088 \\
\hline Porosity & 0.456 & 0.451 & 0.448 & 0.445 \\
\hline $\mathrm{E}_{\mathrm{P}}, \mathrm{GPa}$ & 898 & 888 & 882 & 877 \\
\hline \multicolumn{5}{|c|}{ Initial size $\mathrm{Al}_{2} \mathrm{O}_{3}$ of $200 \mu \mathrm{m}$} \\
\hline Density, kg/m ${ }^{3}$ & 2040 & 2057 & 2072 & 2080 \\
\hline Porosity & 0.4577 & 0.4532 & 0.4492 & 0.4471 \\
\hline $\mathrm{E}_{\mathrm{P}}, \mathrm{GPa}$ & 901 & 892 & 884 & 881 \\
\hline \multicolumn{5}{|c|}{ Initial size $\mathrm{Al}_{2} \mathrm{O}_{3}$ of $320 \mu \mathrm{m}$} \\
\hline Density, kg/m $\mathrm{m}^{3}$ & 2035 & 2050 & 2062 & 2067 \\
\hline Porosity & 0.4591 & 0.4551 & 0.4519 & 0.4506 \\
\hline $\mathrm{E}_{\mathrm{P}}, \mathrm{GPa}$ & 904 & 896 & 890 & 887 \\
\hline \multicolumn{5}{|c|}{ Initial size $\mathrm{Al}_{2} \mathrm{O}_{3}$ of $400 \mu \mathrm{m}$} \\
\hline Density, $\mathrm{kg} / \mathrm{m}^{3}$ & 2028 & 2039 & 2045 & 2049 \\
\hline Porosity & 0,4609 & 0,458 & 0,4564 & 0,4553 \\
\hline $\mathrm{E}_{\mathrm{P}}, \mathrm{GPa}$ & 907 & 901 & 898 & 896 \\
\hline \multicolumn{5}{|c|}{ Initial size $\mathrm{Al}_{2} \mathrm{O}_{3}$ of $500 \mu \mathrm{m}$} \\
\hline Density, kg/m ${ }^{3}$ & 2024 & 2032 & 2037 & 2040 \\
\hline Porosity & 0.462 & 0.4599 & 0.4582 & 0.4577 \\
\hline $\mathrm{E}_{\mathrm{P}}, \mathrm{GPa}$ & 909 & 905 & 902 & 901 \\
\hline
\end{tabular}

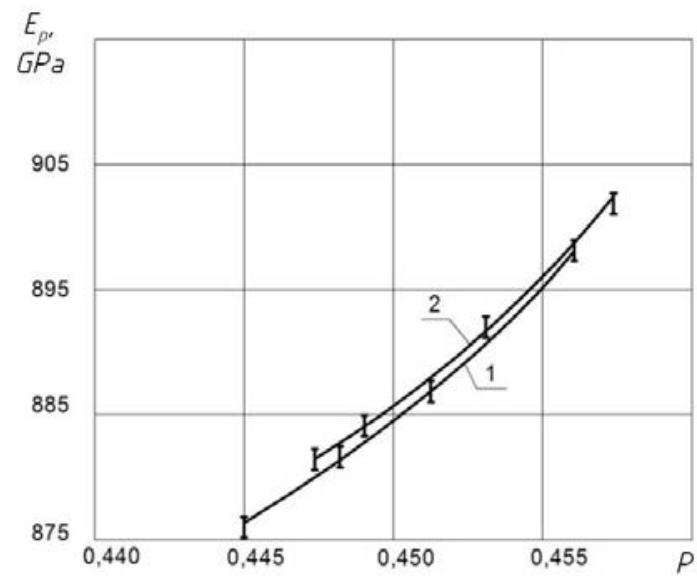

Fig. 3. The impact of porosity (P) of the SCAT compact on the modulus of elongation (Ep) with the $\mathrm{A}_{2} \mathrm{O}_{3}$ grain size of $100 \mu \mathrm{m}$ for 1 and $200 \mu \mathrm{m}$ for 2 . 


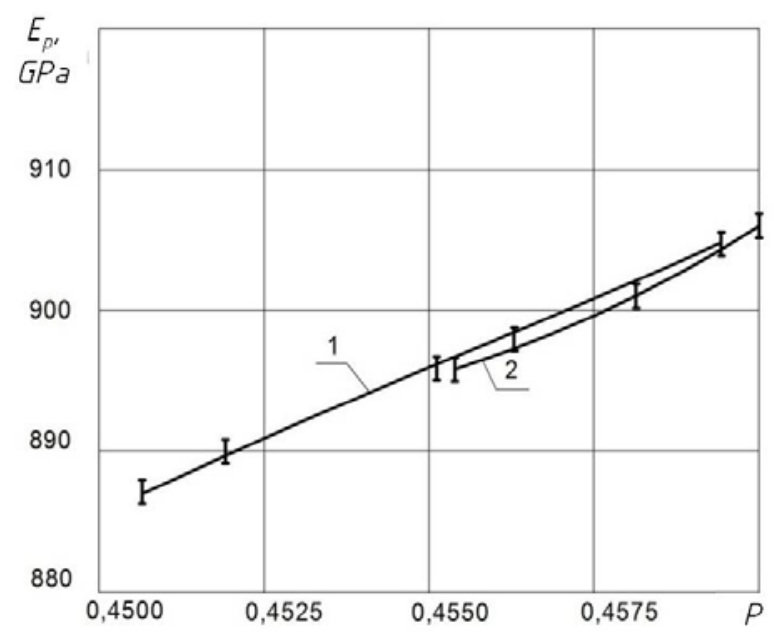

Fig. 4. The impact of porosity (P) of the SCAT compact on the modulus of elongation (EP) with the A12O3grain size of $320 \mu \mathrm{m}$ for 1 and $400 \mu \mathrm{m}$ for 2 .

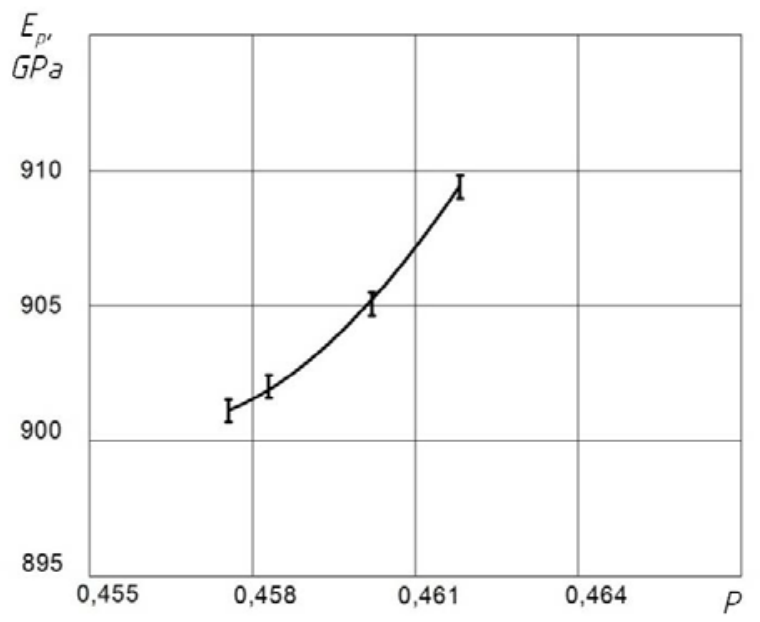

Fig. 5. The impact of porosity (P) of the SCAT compact on the modulus of elongation (EP) with the A12O3grain size of $500 \mu \mathrm{m}$.

In order to predict the SCAT with predetermined characteristics of elastic properties, the empirical dependences between the modulus of elongation and porosity of the compacts (8)-(12) were determined by a well-known method:

for the $\mathrm{A}_{2} \mathrm{O}_{3}$ grain size of $100 \mu \mathrm{m}$ :

$$
\mathrm{E}_{\mathrm{P}}=2023 \cdot \mathrm{P}^{1.034}
$$

for the $\mathrm{A}_{1}{ }_{2} \mathrm{O}_{3}$ grain size of $200 \mu \mathrm{m}$ :

$$
E_{P}=1892 \cdot P^{0.95}
$$

for the $\mathrm{A}_{2}{ }_{2} \mathrm{O}_{3}$ grain size of $320 \mu \mathrm{m}$ :

$$
E_{P}=2008 \cdot P^{1.025}
$$

for the $\mathrm{A}_{2} \mathrm{O}_{3}$ grain size of $400 \mu \mathrm{m}$ :

$$
E_{P}=1967 \cdot P^{1.0}
$$


for the $\mathrm{A}_{2} \mathrm{O}_{3}$ grain size of $500 \mu \mathrm{m}$ :

$$
\mathrm{E}_{\mathrm{P}}=2014 \cdot \mathrm{P}^{1.03}
$$

\section{Conclusions}

According to the results of the research study conducted, we can draw the following conclusions. Under pressure, the shock wave destroyed the abrasive grains and filled the pore space. In this regard, the density of pressing increased and the porosity decreased. Since the elastic characteristics served as a measure of chemical strength and were directly related to the strength of the interatomic bond, the magnitude of the modulus of elongation could be considered as a characteristic of the elastic resistance or elastic hardenability of the material [5].

The practical value of the elastic properties of materials is large. To prevent loss of stability along with constructive measures, materials with a high value of modulus of elongation should be applied. When loading, materials with its lower values accumulate a large supply of elastic energy and therefore must have a high rate of development of microcracks, which of course is their disadvantage [5]. A compact had a slight strength due to the adhesive and cohesive forces of interatomic interaction; therefore it became obvious that an increase in pressure in the the shock wave front leads to a decrease in the modulus of elongation.

\section{References}

1. V. F. Bezyazychny, Problems of improving technological processes of machining parts of high-precision components and products, Appendix. Directory. Engineering Journal, v. 7, pp. 2- 11 (2003).

2. Yu. N. Polyanchikov, M. Yu. Polyanchikova, Method of making abrasive products , Patent of Russia No. 2543024 (2015).

3. G. A. Guly, Equipment and technological processes using electro-hydraulic effect (Moscow: Mechanical Engineering, 1977).

4. A. M. Prokhorov, Physical encyclopedic dictionary (Moscow: Soviet Encyclopedia, 1984).

5. Ya. B. Friedman, Mechanical properties of metals. Part 1. Deformation and destruction (Moscow: Mashinostroenie, 1974). 